\title{
GOOGLE NA CABEÇA! UM ESTUDO SOBRE O SIGNIFICADO DA MARCA
}


GOOGLE NA CABEÇA! UM ESTUDO SOBRE O SIGNIFICADO DA MARCA

Resumo: O artigo tem como objetivo verificar o significado da marca Google, unidade de análise do estudo de caso. A partir das técnicas empregadas, reconheceram-se as principais associações e identificaram-se pontos fortes e fracos da relação estabelecida entre o público e a marca, obtendo-se como resultado a rede neural associativa da marca, além da identificação das fases de percepção da marca, a partir da perspectiva semiótica utilizada.

Palavras chave: Brand equity baseado no cliente; Percepção; Significado da marca; Google

GOOGLE EN LA CABEZA! UN ESTUDIO SOBRE EL SIGNIFICADO DE LA MARCA

Resumen: El artículo tiene el objetivo de evaluar la importancia de la marca Google, la unidad de análisis del estudio de caso. De las técnicas utilizadas, se reconocieron las principales asociaciones y se identificaron fortalezas y debilidades de la relación entre el público y la marca, obteniendo como resultado la red asociativa de la marca, ademas de la identificación de las etapas de la conciencia de marca desde la perspectiva semiótica utilizada.

Palabras clave: Valor de marca basado en el cliente; Percepción; Significado de la marca; Google

GOOGLE IN MIND! A STUDY ABOUT THE BRAND'S MEANING

Abstract: The article has the objective to verify the Google brand's meaning, the unit of analysis of the case study. From the techniques used, the main associations were recognized and identified strengths and weaknesses of the relationship between the public and the brand, obtaining as a result an associative neural network of brand, besides identifying the stages of brand perception from the semiotic perspective used.

Keywords: Brand equity based on the costumer; Perception; Meaning of the brand; Google 


\section{INTRODUÇÃO}

Marcas têm o propósito de identificar, de indicar propriedade, legitimidade. Sua origem data de longo tempo, já que desde a Idade da Pedra, o Homem utiliza símbolos para distinguir e identificar, ou seja, posicionava uma marca, uma referência. Ao longo do tempo sua função básica permanece. Porém, com a evolução humana, logo, a mudança nas formas de consumo, a complexidade que envolve uma marca passou a ser dissecada e detalhadamente estudada.

Ao observar a influência das marcas no cotidiano das pessoas, percebe-se que elas assumem uma função complementar a formação e evolução da personalidade, bem como da percepção acerca dos fatos que as rodeiam. Nesse sentido, emerge a convicção de que as marcas assumem significado, que segundo a definição de McQuarrie, et al (apud Batey, 2010, p. 143), refere-se "as associações denotativas e conotativas produzidas quando um leitor decodifica um texto". Deste modo, tem-se o texto, a marca, que a partir de suas representações visuais, simbólicas, relacionais, etc., é então analisado e interpretado por aqueles que interagem com ele. Como parâmetros, o "leitor" vale-se da denotação, que tange o conceito literal, e também da conotação, que vai além, a ponto de ser subjetivo ou figurado, oriundo de sentimentos e emoções que geram associações, algo intangível e instável.

A fim de compreender o que são marcas em um sentido amplo, toma-se como base a definição de Perez (2004, p. 10): "a marca é uma conexão simbólica e afetiva estabelecida entre uma organização, sua oferta material, intangível e aspiracional e as pessoas para as quais se destina." Assim, além de identificar e diferenciar, as marcas também possuem a função social de aproximar pessoas, uma vez que são capazes de estabelecer relacionamentos entre elas através do que simbolizam. Acima de qualquer questão, a marca é uma entidade pública, construída de maneira colaborativa por aqueles que com ela interagem e estabelecem vínculos.

A partir destes conceitos, identifica-se a necessidade de aferir-se o significado das marcas. Como caso para esta análise, utilizar-se-á a marca Google, uma vez que tem exercido impacto extremo no dia-a-dia dos indivíduos de todo o mundo. Emerge a questão em estudo: qual é o significado da marca Google?

Dada a questão norteadora, tem-se como objetivo principal verificar o significado da marca Google. Também busca-se elaborar e analisar uma rede associativa da marca, além de identificar, a partir da proposta semiótica, as ba- 
ses da percepção da marca. Justifica-se a realização deste estudo, pois poucos são os resultados disponíveis acerca do tema significado da marca, com base em uma perspectiva do público usuário, uma vez que o foco dos estudos está, por vezes, nas mensagens emitidas pelas marcas. Porém, devido aos múltiplos sentidos que uma mensagem pode ter, buscar a atenção e compreensão exige conhecer as expectativas dos receptores, entendê-las e atendê-las.

Para atender aos anseios despertados neste estudo, abordar-se-ão conceitos acerca de brand equity baseado no cliente, identidade e imagem, percepção e significado de marca. Fundamentarão este estudo as teorias de KELLER (2006), BATEY (2010), SANTAELLA e NÖTH (2001) e HILL (2009).

A fim de alcançar as respostas aos objetivos almejados, acredita-se que o caminho a percorrer tem início na adoção e definição de uma pesquisa exploratória (GIL, 1991). Os procedimentos adotados à coleta de dados serão a pesquisa bibliográfica, pesquisa documental, por meio de coleta em documentos oficiais disponibilizados pela marca, bem como outras fontes e mídias sociais; e pesquisa aplicada, por meio de formulário eletrônico, composto de questões abertas e fechadas. Essas técnicas permitirão a realização de um estudo de caso, método aprofundado a partir das elucidações de Yin (2001). Desta forma, após a retratação de aspectos teóricos, que serão aplicados para compreensão dos dados coletados a partir do caso escolhido, será viável o identificar o significado da marca Google.

\section{UMA OUTRA PERSPECTIVA EM BRAND EQUITY}

Dadas as mudanças no comportamento humano de consumo, gerenciar marcas torna-se uma atribuição básica para empresas que desejam manter-se competitivas e em crescimento. Neste sentido, percebe-se também uma evolução no que tange o trabalho de branding, mesmo sendo essa uma atividade relativamente recente, ao menos no campo científico. No princípio, o foco era a marca, e a ela eram direcionadas todas as atenções. Todavia, no tempo em que se está a direção é conhecer e agir junto ao que dá sentido às marcas: as pessoas. Quando trata-se de pessoas, todos os processos tem seu nível de complexidade ampliado, pois fala-se em sentimentos, percepção e outras tantas questões subjetivas, que até então, eram desconsideradas no mundo dos negócios. Porém, é a partir do que é atribuído pelas pessoas que as marcas adquirem sentido e valor. 
Neste rumo, o valor atribuído às marcas pode ser efetivado a partir de técnicas do Brand Equity, que segundo Aaker (1998, p. 16) "é um conjunto de ativos e passivos ligados a uma marca [...], que se somam ou se subtraem do valor proporcionado por um produto ou serviço para uma empresa e/ou para os consumidores dela". Nesta perspectiva, tem-se uma dimensão ampla do valor da marca, pois muitas são as possibilidades a serem avaliadas e atribuídas como ativos e passivos e muitas métricas são usadas para medi-los. Todavia, encontra-se dificuldade em valorar principalmente o que é subjetivo, ou seja, o que é produzido e gerenciado pelas pessoas que se relacionam com a marca.

Atentando a essa necessidade, Keller (2006, p. 36) apresenta um modelo de Brand Equity baseado no cliente (CBBE - Customer-based Brand Equity), cuja proposta "é que a força de uma marca está no que os clientes aprenderam, sentiram, viram e ouviram sobre ela como resultado de suas experiências ao longo do tempo". Em resumo, a percepção transformada em significado.

\section{ESPELHO, ESPELHO MEU: QUEM TU DIZES QUE SOU EU?}

Percepção refere-se à recepção de estímulos e como esses são interpretados. A fim de abranger o processo em si, faz-se essencial compreender o ponto de origem, ou seja, a identidade da marca, que é projetada a partir de diversos estímulos.

Para Costa (2003), as marcas projetam-se essencialmente a partir de seus dados constitutivos, que compreendem sua divulgação formal, e por sua personalidade, que aborda os contatos e experiências proporcionados. Ao encontro, tem-se a posição de Baldissera (2008) acerca de identidade, ou como aborda, processos identificatórios, enfatizando que trata-se de processo provisório e em constantes transformações. O sujeito (marca) comunica e é comunicado a todo o tempo (Baldissera, 2010) e essa relação com o outro, a alteridade, também influencia e compõe a identidade. Dadas as concepções, fica claro que é a partir do que é exposto pelas marcas em sua totalidade, a partir de mensagens enviadas a todo o tempo, seja por meios como a propaganda (oficiais), ou por análise da rotina das organizações (informais), por exemplo, que estão por detrás da marca. Como premissa básica, tem-se então, a necessidade de consonância (ou a sua maior possibilidade) entre o que a marca comunica oficialmente e o que comunica involuntariamente, como as informações informalmente assimiladas a partir do relacionamento estabelecido, por exemplo.

Sobre esse desafio das marcas Baldissera (2004, p. 116) afirma: 
a um só tempo, necessitam-se públicos identificados com a organização (em diferentes temporalidades e intensidades) e imerge-se no espaço - nebuloso, sombrio, portanto pouco praticável e descritível - do mapeamento e apreensão da multiplicidade dispersiva de possibilidades identificatórias dos públicos. (...) Disso infere-se que é pouco provável um ajuste completo, com total conformação entre públicos e organização, ou, ainda, a total simpatia entre organização e públicos.

O autor destaca (e considera improvável) o que é pautado pelas marcas como seu principal desafio: gerar simpatia e fidelização. De fato, isto tem se tornado incerto devido dinamicidade e mudança de cenários e das interações com os públicos, o que exige capacidade de análise e ação que responda às novas exigências dos indivíduos e seus grupos. A diversidade de marcas disponíveis para atender uma mesma necessidade/ desejo, transformou uma aquisição rotineira em uma atividade complexa, pois há questionamento sobre quais são seus pontos de diferenciação, bem como quais desses oportunizarão mais benefícios. E é nesse ponto que a geração anterior e constante de estímulos exerce influencia e garante a escolha por determinada marca, uma vez que a partir da percepção das mensagens enviadas que são (re)criados os vínculos (ou desvínculos) entre ela e os públicos.

Em linhas gerais a percepção trata da recepção dos estímulos através dos cinco sentidos e da interpretação desses estímulos a partir de experiências armazenadas na memória, como história, ambiente físico e social, cultura, características pessoais (psicológicas, fisiológicas e de personalidade). "E estas variáveis são integradas, resultando assim na estrutura cognitiva que permite percepções organizadas e significativas, permite que interpretemos as coisas." (GADE, 1980, p. 47). Formata-se então a percepção, que em primeira instância é inconsciente, pois a resposta ao estímulo é instantânea, sem reflexão. Já em um segundo momento, é consciente, pois provém de um pensamento organizado, ou seja, uma ação raciocinada. Ocorre então, a interpretação dos dados recebidos. Logo, tem-se informação para a tomada de decisão acerca de algum fato.

A partir da teoria semiótica proposta por Peirce, elencada por Santaella e Nöth, a percepção possui três bases, ou momentos distintos e interligados. O primeiro é chamado de percepto ou estímulo, que nas palavras da autora é "aquilo que está fora de nós, apresentando-se à porta dos sentidos, insiste na sua singularidade, compelindo-nos a atentar para ele" (2001, p. 86). Nesta fase, externa ao indivíduo, há a realidade e os fatos que a compõe. Esse contexto 
incita o interesse por seu significado, uma compreensão, que ainda não efetivada, atua como catalisadora na busca por respostas.

$\mathrm{Na}$ fase seguinte, o percepto atinge o nível denominado percipuum, "ou seja, o modo como o percepto se apresenta àquele que percebe, ao ser filtrado pelos sentidos" (SANTAELLA e NÖTH, 2001, p.87), o que representa a interpretação; as respostas anteriormente ansiadas, possíveis devido aos sentidos, que ao reterem, seja por uma compreensão embasada em sentimentos, uma surpresa abrupta, ou através da impessoalidade, no sentido de um estado casual ou direto, sem cargas emocionais, declarado por Santaella et al como 'automatismo dos esquemas mentais', resultam no terceiro estágio, chamado de julgamento de percepção, que é a resposta ao estímulo recebido.

Em síntese, o percepto bate à nossa porta, insiste, mas é mudo. O percipuum é o percepto já traduzido pelos sentidos. Essa tradução pelos sentidos em três níveis, o do sentimento, o do choque e o do automatismo interpretativo, este correspondendo exatamente ao juízo perceptivo, o qual, por sua natureza interpretativa, é aquele que nos diz o que é que está sendo percebido. (SANTAELLA et al., 2001, p. 87).

De forma simplificada, o processo ocorre a partir de um acontecimento que suscita a atenção do indivíduo. Após, por meio de uma seleção realizada pelos sentidos, de diversas formas, é gerada a compreensão do estímulo, que é imediatamente avaliado e é gerada uma percepção acerca do fato ocorrido. É ressaltada a noção de tempo, denominada por Peirce como antecipuum, antecipação de algo que se espera confirmar, e ponecipuum, os registros presentes na memória. Para os autores a percepção só é possível devido à existência destes elementos.

Assim, além de avaliarem-se as condições dos indivíduos, quanto a sentimentos e disponibilidade dos sentidos e o contexto em que ele está inserido, nessa perspectiva, o tempo exerce também influencia direta na percepção gerada. Ao aplicar-se essa teoria quanto ao trabalho de branding, tem-se a marca como em uma posição antecipuum, pois ao planejar suas ações e os pontos de impacto junto aos públicos, prevê um resultado a ser alcançado; uma mensagem a ser compreendida, ao passo que, os receptores valem-se do ponecipuum para avaliarem os dados recebidos e gerarem uma impressão acerca do que fora exposto.

Embasado em uma perspectiva psicológica do processo de percepção, Batey (2010, p. 98) afirma que: 
é o processo pelo qual essa informação sensorial é selecionada, organizada e interpretada. Os dados brutos das nossas sensações são enviados ao cérebro para interpretação. $O$ que adicionamos ou atribuímos dessas sensações quando atribuímos um significado a elas dá o resultado do processo de percepção.

Desta forma, o processo inicia a partir da exposição a determinados estímulos, que podem ser captado por um ou vários de nossos sentidos: visão, olfato, audição, tato e paladar. Esses receptores sensoriais naturalmente fazem a seleção dos pontos principais da mensagem, o que é chamado de seleção perceptiva, "devido à capacidade limitada do nosso cérebro de processar informações, as pessoas tendem a filtrar e selecionar apenas uma pequena quantidade dos estímulos" (BATEY, 2010, p. 129). Certamente, limitações individuais, advindas de um contexto específico e a natureza do estímulo também influenciam na captação dos dados e consequentemente influenciarão na percepção gerada, pois as sensações dependem da disponibilidade do interlocutor em dedicar seu tempo e atenção. Desta forma "(...) o importante é que os pontos de contato sensoriais de uma marca sejam mantidos vivos." (LINDSTROM, 2007, p. 111), ou seja, haja constante trabalho quanto aos estímulos dos sentidos, bem como um aprimoramento, a fim de que seja dedicada a atenção e ocorra a (re)criação de vínculos.

Uma vez conquistada a atenção, por meio de sensações que incitam a continuidade do contato, o cérebro humano realiza conexões com o objetivo de interpretar o que recebe, fase denominada organização perceptiva. Batey (2010, p. 131), baseado na psicologia da Gestalt, afirma que ao receber um dado "o cérebro dá um salto cognitivo do registro das partes para a interpretação do todo". Assim, a partir do que já consta na mente dos indivíduos, os novos estímulos são organizados com a finalidade de preencher espaços que até estão “vazios" ou despercebidos. A partir da junção das partes, novas e já existentes, é possível avançar para a fase seguinte, a interpretação, quando o todo passa a existir na mente do indivíduo, pois encontra significado e é revelada a resposta ao exposto inicialmente. Neste ponto, o contexto sócio-cultural também será definitivo para a compreensão, o que pode ser exemplificado a partir de diferentes descrições de pessoas que presenciaram um mesmo fato.

Podemos sintetizar o processo: 


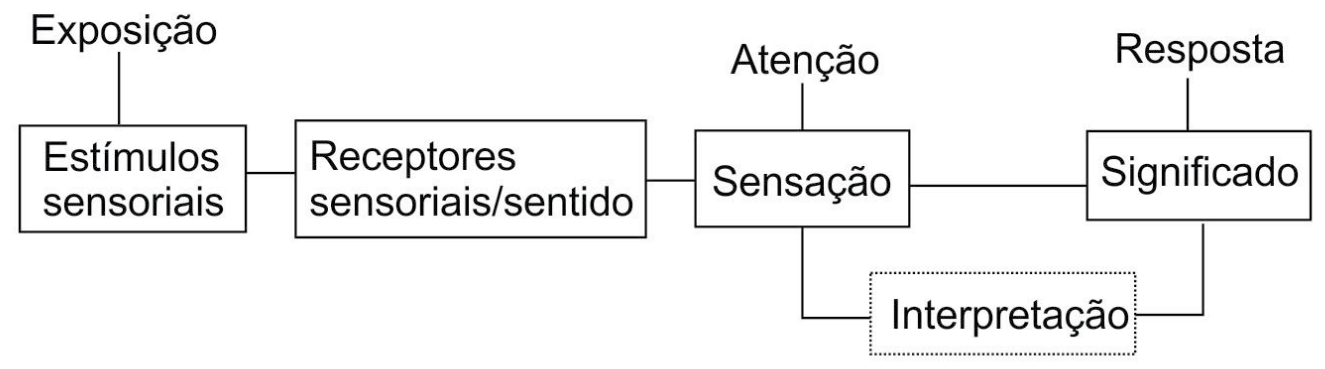

Figura 1 - Processo de percepção

Fonte: Elaborada pela autora com base em Batey (2010)

Desta forma, o projetado por uma marca e percebido por seus receptores, estabelecem a conexão e é gerada a percepção ou imagem. Pondera-se então que é construída com base no significado que possuem os dados emitidos por meio da identidade e seus contextos. Nesse sentido, a ambos, marca e indivíduos, por contínua e mútua influencia, confere-se a responsabilidade de construir e reconstruir significados, devido a relação que estabelecem.

\section{COMO AS MARCAS FICAM NAS NOSSAS VIDAS?}

As marcas, embasadas nas mais diversas formas de apelo, permeiam e incutem-se à memória das pessoas com o foco de tornarem-se presentes e relevantes no momento decisório. Porém, para alcançar esse status, é necessário possibilitar conexões desejadas, sem imposições, que identifiquem e aproximem, obtendo sentido.

O significado da marca, ou o sentido estabelecido, percorre duas instâncias: como a marca é percebida no nível consciente e como ela permanece na mente dos indivíduos, em um nível subconsciente. Desta forma, os extremos, racional e subjetivo, geram uma percepção e interpretação, e então, o significado da marca para aquele indivíduo. A comunhão (ou a semelhança) deste ponto de vista entre os públicos culminará na elaboração do significado da marca para aquela comunidade, tornando-se uma entidade mantida e influenciada por essa e pela marca (BATEY, 2010).

No momento da escolha por determinada marca, racional e emocional convergem. Esse processo explica-se, pois, estruturalmente, o cérebro humano divide-se em três partes: instintos, emoções e razão. A primeira parte, chamada de sistema original, é responsável pela comparação entre as situações atuais 
e passadas, enquanto o segundo, límbico, onde o que é captado através de meios instintivos é moldado, a fim de que representem a compreensão do que foi apreendido, logo a resposta. A terceira parte, conhecida como neocórtex, corresponde ao processamento de dados, ou seja, a mente. (HILL, 2009)

No momento em que mensagens são emitidas aos indivíduos e ocorre, mesmo que de forma superficial, experiência com a marca, os sistemas cerebrais trocam dados entre si, e devido a convergência realizada entre esses dados, são criados vínculos, que permitem seu reconhecimento.

[...] as marcas são codificadas na memória em uma base cognitiva (pensada, analisada, considerada) e emocional (somática). Esses dois elementos da codificação de uma marca são umbilicalmente legados e determinam se as pessoas prestam ou não atenção aos estímulos vindos da marca (BATEY apud GORDON, 2010, p. 194).

Hill (2009) agrega a percepção de Batey (2010), valendo-se de questões orgânicas, já que no cérebro humano o hipocampo e a amígdala são as esferas responsáveis pelas recordações em nossa memória, e ambos estão situados no sistema límbico. A partir disso, evidencia-se que nossas ações são motivadas por emoções, uma vez que a racionalidade nos permite apenas a compreensão dos dados recebidos e o cruzamento dos mesmos. Porém, a seleção realizada previamente, que é unicamente sensorial e instintiva, mostra que escolhemos pelo vínculo emocional que fora estabelecido em momentos anteriores. Assim, concebe-se que no processo decisório, independente do tema, o que inclui as marcas, os seres humanos valem-se dos sistemas sensório e emocional, já que as escolhas são em verdade realizadas de forma "rápida, emocional e subconsciente; em resumo, é intuitivo" (HILL, 2009, p. 16).

Tem-se então o ponto fundamental: as emoções. Para Lindstrom (2007, p. 161) "as emoções são importantes, porque podem ajudar a explicar por que as pessoas têm um comportamento determinado". O autor propõe que os estudos realizados pelas marcas devem proceder das emoções, para então optar por determinados estímulos aos sentidos, o que facilita a compreensão das mensagens implícitas das marcas. Conhecer o significado das emoções permite o uso de técnicas que as estimulem de acordo com os interesses de marca. Uma vez que as emoções determinam comportamentos e impulsionam à ação, logo, funcionam como motor, torna-se displicência desconsiderá-las, quando o principal objetivo está em motivar o consumo. 
Como última instância, o significado pode ser simbólico. É a partir da apreensão do significado simbólico que as pessoas definem suas escolhas e desempenham seus papéis. A atitude perante as situações postas, deriva do contexto social, dos valores ou qualquer outro aspecto que o inclua em um determinado grupo. Dessa forma, as escolhas não são individuais, mas referenciam um balanço entre motivações físicas, biológicas e psicológicas, com os acordos sociais que regulam a sociedade.

Neste sentido, Batey (2010, p. 144) afirma que “(...) se aceitarmos que o significado pode ser alcançado por associações, é imperativo que se identifique quais associações mais definem o significado de um objeto ou de uma marca." As associações de marca são base para a identificação do ponto principal deste estudo: o significado da marca. Supõe-se, por esta afirmação, que assim como a percepção, as associações são elementos que habitam a mente dos indivíduos, uma vez que neurologicamente são processadas "as conexões entre os diferentes neurônios ativos são reforçadas e esse padrão específico de atividade cerebral gera o engrama." (BATEY, 2010, p. 29). O resultado é a fixação dos dados recebidos e processados pelos neurônios, que conforme a intensidade implicará na lembrança da situação vivida e na percepção do estímulo.

Entretanto, Aaker (1998), percebe as associações sob o ângulo das marcas, dando ênfase ao que é emitido, comunicado, cuja análise está focada no resultado, ou seja, nos benefícios que as associações trazem às marcas, enquanto na proposta de Batey e Keller, o enfoque reside na forma como os dados são processados, o que é relevante para o reconhecimento das associações. Aaker afirma que elas impõem o valor da marca, uma vez que ajudam na localização da informação, diferenciam, impelem à ação e criam sentimentos positivos sobre ela.

Para que seja possível a identificação das associações, faz-se necessário categorizá-las, a fim de agrupar as respostas semelhantes e estabeleça-se de maneira clara seu significado. Aaker ${ }^{1}$ (1998) apresenta onze diferentes possibilidades de associação. Sob outra perspectiva, Keller (2006) e Batey (2010) elencam três, embasadas nos atributos (racionais e emocionais), benefícios (funcionais, sensoriais, expressivos e emocionais) e atitudes (racionais, conscientes, irracionais e inconscientes).

O conjunto de associações de marca gera uma rede associativa, que con-

1 Neste estudo a base será a proposta por Batey, 2010. Para aprofundamento da proposta de David A. Aaker sugere-se a consulta da obra: Marcas - Brand Equity: gerenciando o valor da marca. 
forme a proposta de Batey (2010, p. 209) “(...) é uma representação da marca no tempo presente. Reflete como a marca é percebida". Em suma, a rede mostra os estímulos, puros ou transformados, que permanecem na lembrança das pessoas. Quando compreende-se, a partir do exposto, que, o grupo de associações refere-se ao significado da marca, pode-se conceituá-lo como o conjunto de associações, essencialmente emocionais, presentes na lembrança e aos quais as pessoas recorrem para optar por determinada marca. Aceita-se, consequentemente, que, quando um determinado grupo atribui associações semelhantes a uma mesma marca, este significado passa a ser coletivo, deixando de habitar apenas na mente de um indivíduo.

\section{E PARA VOCÊ: O QUE O GOOGLE SIGNIFICA?}

Após a apreensão dos conceitos de percepção e significado, bem como de suas bases, emoções e associações, busca-se aplicá-los a fim de alcançar os objetivos propostos. Para tanto, usar-se-á como base a marca Google, que como tal concretiza-se como empresa em 1998. Porém, a história inicia-se tempos antes, em 1996, quando os então acadêmicos do doutorado em Stanford (EUA), Larry Page e Sergey Brin, decidem compartilhar os estudos e criar uma ferramenta eficaz de pagerank. Apesar das dificuldades para venda da tecnologia, que nunca concretizar-se-ia, o sonho dos (agora) empresários tornara-se realidade por suas próprias mãos e atualmente a marca é reconhecida pela credibilidade de seus serviços, que se ampliaram amplamente, assim como o seu valor, uma vez que em 2010 e 2011 o ranking Interbrand ${ }^{2}$ divulga o Google na quarta posição dentre as marcas mais valiosas do mundo.

A fim de analisar a percepção de marca neste caso, utilizar-se-ão duas abordagens: a primeira, baseada nas afirmações de Santaella e Nöth (2001) e a segunda a partir das referências apresentadas por Keller (2006) e Batey (2010). Para atender ambas, já que priorizam a busca de informações junto aos indivíduos, realizou-se uma coleta de dados referentes a marca Google, por meio da aplicação de questionário online, composto de perguntas abertas e fechadas, no período de 27 de setembro a 07 de outubro de 2010. A amostra compôs-se

2 http://www.interbrand.com/en/best-global-brands/Best-Global-Brands-2010.aspx, acesso em 18/01/2010, às 2oh e http://www.interbrand.com/en/best-global-brands/Best-Global -Brands-2011.aspx, acesso em 07/02/2012, às $20 h$. 
de funcionários técnico-administrativos da Universidade Feevale (RS), sendo a adesão correspondente a $16,97 \%$, ou seja, 145 participantes. O público ${ }^{3}$ é formado em maioria pelo sexo feminino, sendo a faixa etária predominante de 20 a 25 anos e residente na cidade de Novo Hamburgo. Destaca-se o grau de instrução superior em andamento, e a renda mensal de $\mathrm{R} \$ 500,00$ a $\mathrm{R} \$ 1.500,00$.

Com base na teoria de Santaella e Nöth (2001) a percepção passa por três fases, conforme elucidado anteriormente. Na figura abaixo condensa-se as bases norteadoras da análise:

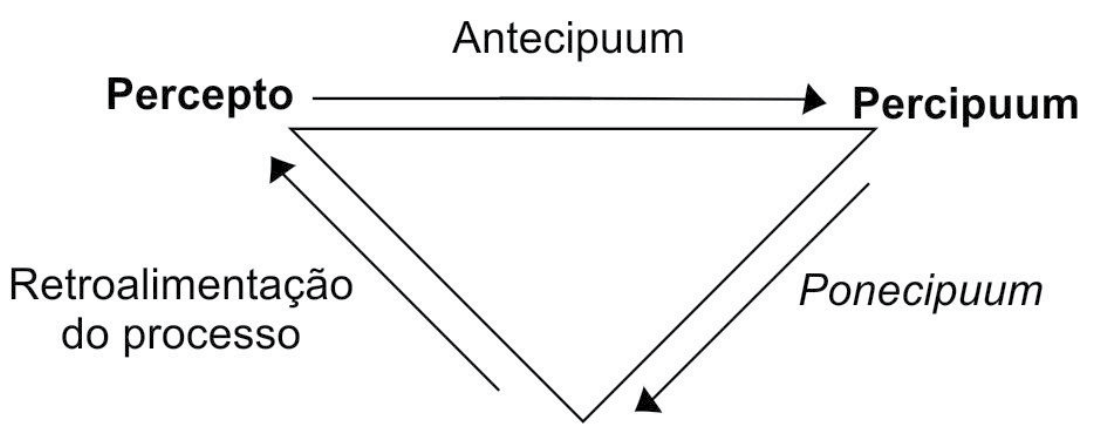

Julgamento de percepção

Figura 2 - Processo de Percepção a partir de Santaella e Nöth (2001)

Fonte: elaborado pela autora

Como referências para a identificação da primeira fase, o percepto, as respostas indicam o uso dos diversos produtos ofertados pelo Google, além da frequência em que a marca é lembrada pelos entrevistados (48\% afirma pensar nela várias vezes ao dia). Percebe-se que esta é a principal forma de divulgação utilizada por ela, sendo isso evidenciado em sua página corporativa: "A utilidade e a facilidade de uso do Google o tornaram uma das marcas mais conhecidas do mundo, quase totalmente divulgado através do boca-a-boca de usuários satisfeitos." 4 O Google surgiu como buscador, com o propósito de tornar-se referência em conteúdo relevante para o usuário, no local e momento em que este julgar necessário. Desta forma, o que incita, essencialmente, é a curiosida-

3 Informações gerais sobre os participantes da pesquisa. Como qualificação da amostra destaca-se:Sexo: 64\% feminino e 36\% masculino; faixa etária de 20 a 45 anos, de diversas cidades do Vale dos Sinos e região metropolitana de Porto Alegre. 39\% possuem ensino superior concluído e 55\% em andamento. O questionário foi aplicado em janeiro de 2011.

4 http://www.google.com.br/intl/pt-BR/corporate/index.html 
de por determinado tema, que por ser esclarecido de forma satisfatória, torna como vínculo principal o meio utilizado, que no caso, é o canal da marca.

Outro ponto refere-se às notas que remetem ao valor da marca, a forma de trabalho, a cultura e a satisfação dos colaboradores, que recebem destaque em diversas publicações de renome mundial, uma vez que usuários querem compreender a forma de trabalho e estratégia de negócio da marca. Segundo ela, "uma equipe que reflete o público-alvo global atendido pelo Google".

Os dados coletados com o questionário revelam ainda que a marca se apresenta como prática e com qualidade incomparável, percepções que convergem com o que é almejado por ela, em suas ações e seu foco de atuação. Percebe-se que frente à concorrência do negócio principal do Google, a marca tem supremacia inquestionável, pois atende às expectativas de seus usuários de forma consideravelmente satisfatória.

O Google é lembrado principalmente por ser ilimitado, ou seja, dúvidas das mais diversas são sanadas facilmente acessando o buscador da marca, ampliando os horizontes por meio do conhecimento. Por vezes, os participantes da pesquisa salientam a simplicidade para localização de serviços, dentre outras informações relevantes, o que facilita seu dia-a-dia. Não restam dúvidas, que o sucesso do Google está na facilidade quanto à acessibilidade, possivelmente oriundas da transformação social, já que atualmente exigem-se respostas rápidas, além da multiplicidade de funções acumuladas pelos indivíduos, que amplia sua gama de ações, assumindo diferentes papéis, e de sua formação básica e profissional.

Como principais sentimentos/sensações estimulados pela Google têm-se diversão e segurança. Supõe-se que o Google tem como diferenciais oferecer respostas corretas, no momento em que o seu usuário necessita, de forma prática e segura. A diversão oportunizada pela mutação diária do logo da marca, por meio de acréscimo em conhecimento é algo notado e aprovado por aqueles que usam seus serviços, já que muitos dos participantes da pesquisa citaram esse fato.

Para relação com a segunda fase do processo de percepção, o percipuum, em que há a ligação mental dos elementos assimilados, utilizam-se as respostas dos usuários entrevistados, que indicam os sentimentos ligados a diversão, que são coerentes com: logo da empresa, escritórios, dinâmica de trabalho, serviços oferecidos, práticas de relacionamento com os colaboradores, divulgações geradas pela empresa (em seus sites como Orkut, YouTube e o próprio Google) em que é revelada missão da marca, bem como outras oriundas de veículos gerais e especializados. 
Para compreensão desta fase, também analisam-se temas focados nas questões corporativas da marca, que foram avaliadas e valoradas. Para o público pesquisado a marca é administrada de maneira competente, pois possui clara visão de futuro, apresentando possibilidades de crescimento. A mesma convicção não é apreendida quando trata-se da análise das ações ligadas a responsabilidade ambiental, social e transparência, já que acerca destas não há identificação ou ciência, mas uma suposição de que a marca atue de forma adequada nestes pontos.

Em questões com enfoque na relação direta com a marca, como confiança, atenção às necessidades dos usuários e também acerca do grau de importância dado a sua opinião, reconhece-se incerteza quanto as interações com a marca, além da fragilidade nos elos de aproximação, que apresentam-se pouco estreitos e estáveis, o que frente a concorrência é diferencial para permanecer-se, ou não, vinculado a marca. Reflexo disso pode ser percebido pela perda de share no espaço online, que até então tinha seu domínio, mas que é dividido com o Facebook5. O diálogo é exigência dos públicos, a fim de se estabelecer um relacionamento, com retorno para ambas as partes. Isso compreende a análise das necessidades e desejos, das dúvidas, expectativas, e principalmente do respeito àquele que de alguma forma é responsável pela visibilidade da marca, como os consumidores, por exemplo. As marcas, orientadas por seus gestores, devem estar prontas para de fato comunicar-se com seus públicos, ou estes buscarão quem o faça.

Como última fase do processo apresentado por Santaella e Nöth, o julgamento de percepção, que pôde ser convergido com as proposta de Batey (2010) e Keller (2006) e revelada a percepção da marca. Assim, tem-se a apresentação de do que significa a marca Google, a partir da posição do público pesquisado, que, contudo acredita-se, revelar a percepção da comunidade usuária da marca, o que pode ser visualizado na figura 3, que apresenta o esquema da rede neural associativa. O Google é reconhecido, essencialmente, por seu canal de busca e através deste conquistou a confiança de seus públicos, o que permitiu a extensão e a supremacia da marca frente aos concorrentes.

Divertida, ágil, ousada, dinâmica e original, também são características atri-

5 Conforme notícia da Globo.com, em 30/12/2010, sobre o site Facebook.com ter superado o número de acessos ao Google no ano de 2010, em comparação ao buscador e a rede social. Porém, avaliando os demais serviços, o Google permanece mais acessado. http://g1.globo. com/tecnologia/noticia/2010/12/facebook-supera-googlecom-como-site-mais-visitado-nos -eua.html 
buídas ao Google e são justificadas pelo posicionamento da marca, seus serviços e a forma de trabalho. Percebe-se que há alinhamento entre o que é projetado pela marca e é percebido pelos usuários, o que revela um planejamento quanto às ações e aos serviços que por ela são prestados, a fim de atender aos anseios dos usuários, que exigem respostas rápidas e um canal que condense os serviços disponíveis, otimizando o tempo de acesso, dentre outras tantas necessidades estimuladas pelas mudanças sociais.

Como associações centrais da marca, ou seja, as principais conexões fixadas na mente de seus usuários destacam-se: conhecimento, propiciado pelas respostas relevantes e seguras, geradas com rapidez; reconhecimento da marca por seus elementos como as letras coloridas e também as diferentes mutações atribuídas a logo; e por fim os serviços, que apesar de portarem nomes diferentes, são relacionados diretamente com a marca a partir da dinâmica das cores e movimentos, além do fato de que essa diversidade atenda de maneira mais ampla o que buscam os usuários, premissa propagada pela marca.

A rede neural sintetiza as principais conexões com a marca, a partir do apontado de forma dissertativa pelo público integrante da pesquisa. Observa-se que o significado da marca está ligado a diversas questões racionais, em equilíbrio com a presença de elementos ligados às emoções. Percebe-se que os usuários estão satisfeitos principalmente com a funcionalidade dos serviços, o que garante o relacionamento até o momento em que ocorra alguma falha. A partir de então, o apego emocional será fundamental para a permanência das percepções já estabelecidas pela marca e também para que novas experiências sejam buscadas. 


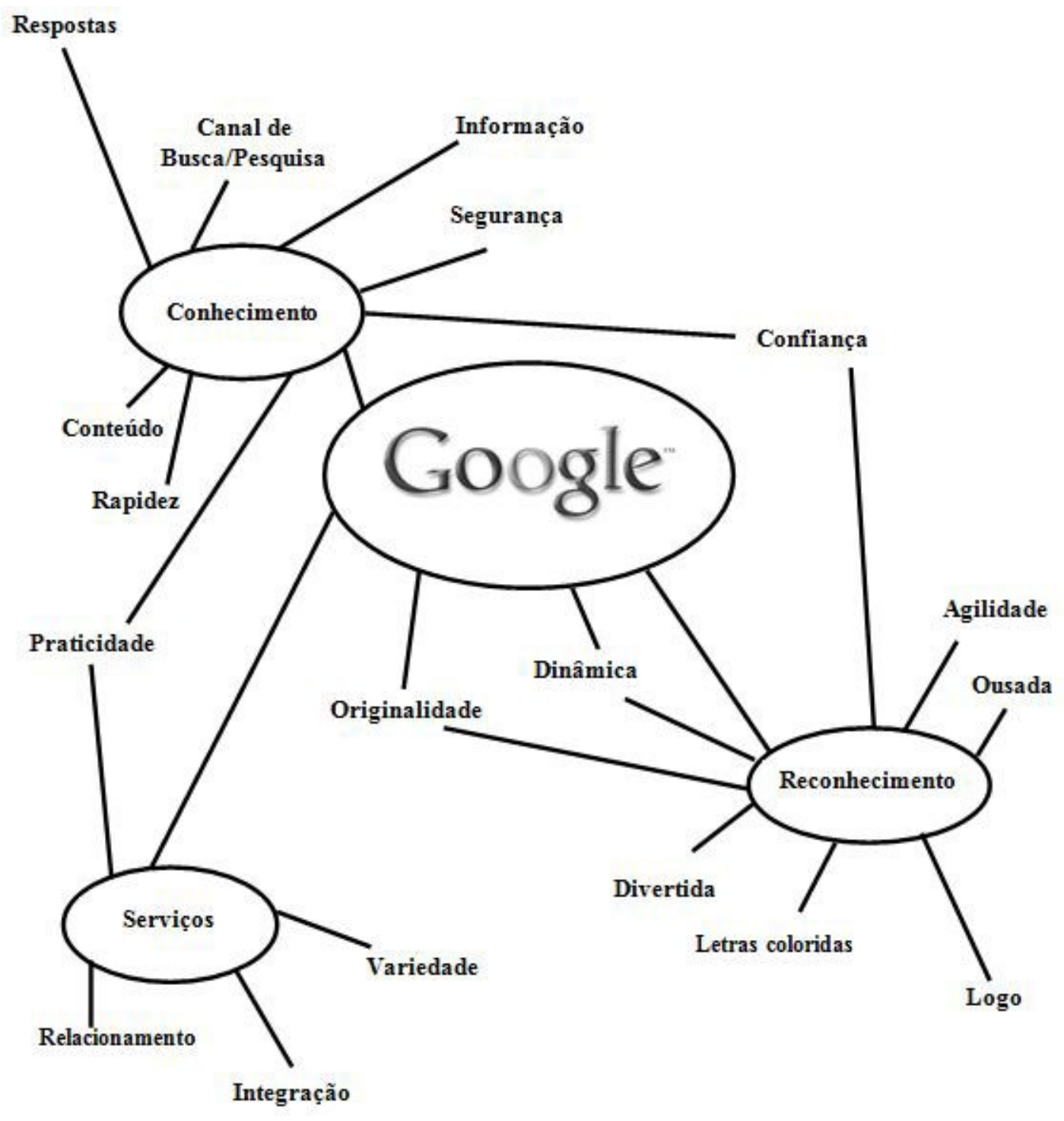

Figura 3 - Rede Neural Associativa de uma Marca - Google Fonte: Elaborado pela autora.

Para elaboração da rede neural, tem-se como base a proposta de Batey (2010), sendo as associações distribuídas nos três blocos: atributos, a partir da ramificação ligada aos serviços, benefícios, com as expressões conectadas ao conhecimento e por fim as atitudes, observadas nos vínculos com o reconhecimento. Percebe-se que apesar da divisão geral, as associações interligam-se e por isso simbolizam e apresentam o significado de marca.

Destaca-se que a confiança é uma associação intimamente ligada ao conhecimento, devido a assertividade das informações que retornam a partir das buscas, o que é base para o reconhecimento da marca. Observa-se a noção de praticidade por ela proporcionada enquanto atributo racional que culmina em um benefício com fins funcionais e emocionais. 
Com base nos objetivos que levam ao uso dos serviços prestados pela marca, os benefícios percebidos devem-se essencialmente ao canal de busca, uma vez que destacam-se associações quanto ao conteúdo, que atende às necessidades no momento em que estas estão mais latentes, sendo esse um dos principais fatores para a credibilidade da marca. O reconhecimento evidencia estímulos sensoriais ligados a elementos de personalidade, com relevo aos visuais, que atribuem similaridade ao visado e obtido pela marca. Já os serviços vinculam atributos racionais e emocionais relevantes, que permitem a experiência com a marca e representam momento crucial para o estabelecimento da marca.

Por fim, resume-se a rede neural destacando-se que a partir da experiência junto aos serviços disponibilizados pela marca, percebem-se os benefícios ligados ao conhecimento oportunizado, ponto de maior referência da marca, o que faz do Google uma marca reconhecida por suas atitudes coerentes com sua essência, o que é percebido e valorado pelos públicos.

\section{CONSIDERAÇÕES FINAIS}

Apresentados os temas brand equity baseado no cliente, percepção, emoções e rede neural associativa, é chegado o momento de refletir os aspectos referenciados neste estudo. A partir de bibliografias acessadas atenta-se as mudanças nas perspectivas ligadas às marcas atualmente, considerando que estas ocorrem de maneira cada vez menos controlável, apesar de todo aparato tecnológico, uma vez que o sucesso das marcas está ligado diretamente à complexidade da mente humana, sendo difícil sua a compreensão completa. Contudo, mesmo com este elemento dificultador, as marcas possuem uma ferramenta que utilizada de forma correta, pode apoiar nas decisões no valor da marca: a comunicação.

Neste sentido, sugere-se o uso das mais diversas tecnologias, já criadas ou as que virão, sem desconsiderar um aspecto básico: a essência está nas pessoas, nas emoções que as motivam, em sua história, fatores que, conforme citado anteriormente por Hill, são fundamentais para a tomada de decisão. Isso implica em gerar meios que, conforme especificidades de cada público permitam a sua manifestação, e que esta seja avaliada e ponderada quando da oferta de produtos e serviços. Neste sentido destaca-se a visão diferenciada de Keller, para quem o valor da marca está focado no que ela significa para aqueles que com ela tem relação.

A relação entre marca e públicos pouco difere de outras relações pessoais 
que todo o ser humano cultiva em sua existência. Não fosse o fato da relação comercial/financeira, em nada mudaria a forma de condução. Desta forma, as marcas precisam de valores, princípios, visões aos quais elas mesmas sejam fieis, para então transmiti-los para quem os consomem. Assim como nas relações pessoais, o sentimento de troca tem de ser preponderante, para que o valor atribuído seja real e permanente.

Desta forma, justifica-se realizar pesquisas a fim de conhecer a percepção dos públicos, pois além de permitir a apreensão do que a marca para eles significa, também comporta informações que podem ser base para novos produtos e serviços, além de aspectos a aprimorar e ampliar o valor da marca. De posse destas informações será possível também elaborar um esquema com a rede das associações com a marca, o que também revela as principais formas de estimulam sua escolha e as fontes para conhecer e reconhecê-la.

No caso analisado neste estudo, entende-se que o Google possui paridade no seu posicionamento em relação ao que percebem os usuários participantes da amostra, o que demonstra que um trabalho simétrico de comunicação é realizado, uma vez que suas ações refletem o dia-a-dia da marca e este fato permite uma aproximação entre ela e seus usuários. Em contrapartida, identifica-se que a relação entre ambos tem aspectos a evoluir, pois elementos ligados ao relacionamento, como ouvir e importar-se com a opinião, mostram-se dúbias para o público.

Constata-se então o significado, que parte das associações centrais de marca, identificadas como conhecimento, serviços e reconhecimento. Estabelecese como um canal de busca, cuja confiança é inquestionável por parte de seus usuários. A percepção identificada com base na proposta semiótica é resultado de um trabalho de relacionamento realizado pela marca, uma vez que o público reconhece e propaga seu valor. Percebe-se isto, a partir de declarações como as identificadas na pesquisa realizada, como por exemplo: "Acredito que a marca deveria se transformar em verbo. Ao em vez de dizer vou procurar no Google, diríamos, vou 'googar'”. Tal prestígio deve-se a identificação concedida pela marca ao público, quando visa oferecer serviços diferenciados que agreguem ao que é almejado, sendo isto visado e valorado por todos os públicos que relacionam-se com a marca.

Assim, a partir dos resultados apresentados, acredita-se que os objetivos propostos tenham sido alcançados, pois a partir dos procedimentos adotados foi possível elucidar o significado da marca Google, além de compreender a per- 
cepção através de suas associações. Desta forma, acredita-se colaborar com os estudos na área, uma vez que este corrobora com as teorias apresentadas.

\section{REFERÊNCIAS}

AAKER, David. Marcas: brand equity gerenciando o valor da marca. São Paulo, SP: Negócio Editora, 1998. $300 \mathrm{p}$.

BALDISSERA, Rudimar. Imagem-conceito: anterior a comunicação, um lugar de significação. Porto Alegre, RS: Tese de Doutorado apresentada ao Programa de Pós Graduação em Comunicação, PUCRS, jun. 2004. 295p.

. A complexidade dos processos comunicacionais e interação nas organizações. In: MARCHIORI, M (org). Faces da cultura e da comunicação organizacional. São Caetano do Sul, SP: Difusão Editora, 2010. P 199 - 213.

. Comunicação organizacional: uma reflexão possível a partir do paradigma da complexidade. In: OLIVEIRA, I. L., SOARES, A. T. N. (org). Interfaces e tendências da comunicação no contexto das organizações. São Caetano do Sul, SP: Difusão Editora, 2008. P 149 - 177.

BATEY, Mark. O Significado da marca. Rio de Janeiro, RJ: Best Business, 2010. 398p.

COSTA, Joan. Imagen corporativa en el siglo XXI. 2. ed. Buenos Aires: La Crujía, 2003. 254 p.

GADE, Christiane. Psicologia do consumidor. São Paulo, SP: EPU, 1980. 186p.

GIL, Antônio Carlos. Como elaborar projetos de pesquisa. 3. ed. São Paulo, SP: Atlas, 1991. $159 \mathrm{p}$

HILL, Dan. Emotionomics. Rio de Janeiro, RJ: Elsevier, 2009. 345p.

KELLER, Kevin Lane. Gestão estratégica de marcas. São Paulo, SP: Pearson Prentice Hall, 2006. 277p.

LINDSTROM, Martin. Brand sense. Porto Alegre, RS: Bookman, 2007. 240p.

PEREZ, Clotilde. Signos da marca: expressividade e sensorialidade. São Paulo, SP: Pioneira Thomson Learning, 2004. 174p.

SANTAELLA, Lucia; NÖTH, Winfried. Imagem: cognição, semiótica e mídia. 3. ed. São Paulo, SP: Iluminuras Ltda., 2001. 222p.

VISE, David A.; MALSEED, Mark. Google. Rio de Janeiro, RJ: Rocco, 2007. 346 p.

YIN, Robert K. Estudo de caso: planejamento e métodos. 2. ed. Porto Alegre, RS: Bookman, 2001. $205 \mathrm{p}$.

RECEBIDO EM: 10/08/12

ACEITO PARA PUBLICAÇÃO: 19/10/12 


\section{Gislene Feiten Haubrich}

Especialista em Comunicação Estratégica e Branding (UMayor e Universidade Feevale). Graduada em Comunicação Social (Universidade Feevale). Bolsista de Aprimoramento Científico na Universidade Feevale.

\section{Cíntia da Silva Carvalho}

Doutora e Mestre em Comunicação Organizacional pela PUCRS. Professora, pesquisadora e coordenadora do MBA em Comunicação Estratégica e Branding da Universidade Feevale/UMayor. 